\title{
Effects of Mannooligosaccharides from Coffee Mannan on Fat Storage in Mice Fed a High Fat Diet
}

\author{
Izumi Takao, ${ }^{a}$ Shigeyoshi Fujii, ${ }^{*}, a$ Asako Ishii, ${ }^{b}$ Li-Kun Han, ${ }^{b}$ Toshio Kumao, ${ }^{a}$ Kazuto Ozaki, ${ }^{a}$ \\ and Atsushi Asakawa ${ }^{a}$
}

${ }^{a}$ Research and Development Dept., Ajinomoto General Foods, Inc., Sanken Bldg., 3-25-1, Hyakunin-cho, Shinjuku-ku, Tokyo 1690073, Japan and ${ }^{b}$ Faculty of Environmental and Symbiotic Sciences, Prefectural University of Kumamoto, 3-1-100 Tsukide, Kumamotoshi, Kumamoto 862-8502, Japan

(Received March 21, 2006; Accepted March 25, 2006)

\begin{abstract}
Mice were fed either a high fat diet or a high fat diet containing $1 \%$ mannooligosaccharides (MOS) for twelve weeks. The effects of MOS on fat accumulation and excretion were examined. After twelve weeks, the percentage weight of the fat and hepatic triglyceride level were significantly lower in the MOS group than that of the control group $(p<0.05$ and $p<0.01$ respectively). Furthermore, the serum triglyceride level had a decreasing tendency in the MOS group $(p=\mathbf{0 . 0 5 8})$. On the other hand, the fecal triglyceride level as well as the amount of fat excreted significantly increased in the MOS group $(p<0.05)$. This study showed that the administration of MOS lessened the fat accumulation in the parametrial adipose tissue and the liver while at the same time increased the amount of fat being excreted. These results indicate that MOS may prevent the fat storage through inhibiting the intestinal absorption of dietary fat in a high fat diet.
\end{abstract}

Key words — mannooligosaccharide, fat weight, hepatic triglyceride, serum triglyceride, fecal triglyceride

\section{INTRODUCTION}

Mannooligosaccharides (MOS) from coffee beans (hereinafter referred to as MOS) are non-digestible oligosaccharides principally composed of mannose, which is derived from hydrolyzing mannan in spent coffee grounds at a high temperature and pressure. ${ }^{1)}$ Previous studies have revealed that MOS can promote the growth of bifidobacteria in

\footnotetext{
*To whom correspondence should be addressed: Research and Development Dept., Ajinomoto General Foods, Inc., Sanken Bldg., 3-25-1, Hyakunin-cho, Shinjuku-ku, Tokyo 169-0073, Japan. Tel.: +81-3-5338-6775; Fax: +81-3-5338-6777; E-mail: Shigeyoshi_Fujii@agf.co.jp
}

the intestines and improve the fecal characteristic on human subjects. ${ }^{2)}$ We have recently been investigating alternative physiological functions of MOS from various perspectives. Asano et al. reported the result of their long-term clinical study on human subjects: A daily intake of a $300 \mathrm{ml}$ drink containing MOS ( 1 or $2 \mathrm{~g} / 100 \mathrm{ml}$ ) lowered the level of abdominal and subcutaneous fat when administered everyday for twelve weeks. ${ }^{3)}$ Kumao et al. examined the effect of MOS on fat absorption during meals on human subjects. The result suggested that MOS could inhibit the intestinal absorption of fat. ${ }^{4)}$ The inhibition of fat absorption seems to be part of the mechanism of MOS fat reduction function. However, the additional research is needed to reveal the mechanism. In this experiment, mice were fed a high fat diet over a long period to examine the effect of MOS on fat accumulation and excretion. The quantity of organic acids and microbiota in the cecum were also examined. Furthermore, the serum and hepatic triglyceride levels were measured in order to understand fat metabolism in mice subjected to a high fat diet.

\section{MATERIALS AND METHODS}

Preparation of MOS _ MOS were prepared as described in a previous paper. ${ }^{1}$ Spent coffee grounds were hydrolyzed in a reactor that was kept at $220^{\circ} \mathrm{C}$. The hydrolyzed product was decolorized by activated carbon powder, and desalted by cation exchange resin and anion exchange resin. Monosaccharides were eliminated using active carbon chromatography with a stepwise gradient of water and $10.0 \%(\mathrm{v} / \mathrm{v})$ ethanol. The purified solution was concentrated in a rotary evaporator and lyophilized. The MOS mixture (mannose; $0.4 \%$, degree of polymer- 
Table 1. Composition of Experimental Diets (\%)

\begin{tabular}{lcc}
\hline \hline Components & Control (\%) & MOS (\%) \\
\hline Beef tallow & 39 & 39 \\
Sunflower oil & 1 & 1 \\
Corn starch & 10 & 10 \\
Sugar & 9 & 9 \\
Mineral mixture $^{a)}$ & 4 & 4 \\
Vitamin mixture $^{a)}$ & 1 & 1 \\
Casein $^{\text {MOS }}$ & 36 & 35 \\
\multicolumn{2}{c}{ MOS: mannooligosaccharides. a) Mineral and vitamin mix- } \\
ture: composition of AIN-76 (CLEA Japan Inc.).
\end{tabular}

ization (dp) $2 ; 19 \%, \mathrm{dp} 3 ; 27 \%, \mathrm{dp} 4 ; 21 \%$, dp5; $17 \%$ and dp6 or more; $14 \%$ ) was used for animal test. Target Group and Preparation of the Experimental Diet — Table 1 shows the composition of the high fat diets used in this experiment. The control group was fed the high fat diet. The MOS group was given the same diet with the addition of $1 \%$ MOS. Animals — The ICR strain of female mice (3 weeks old) was purchased from CLEA Japan Inc. (Tokyo, Japan). In order to ensure proper quarantine and acclimatize the animals to the new environment, they were placed in care for 7 days after the delivery. Only those animals with no abnormalities in their overall physical state were used in this experiment. This experiment was performed in compliance with the Standards Related to the Care and Management of Experimental Animals (Notification No. 6, March 27, 1980, of the Prime Minister's Office), which are based on the Study for the Humane Treatment and Control of Animals (Law No. 105, 1973).

Care Conditions — The animals were placed in a movable rack made of stainless. The room was kept at a temperature of $23 \pm 1^{\circ} \mathrm{C}$, a humidity of 55 $\pm 5 \%$, and under a $12 \mathrm{hr}$ alternating light/dark cycle (artificial lighting: 7 am to $7 \mathrm{pm}$ ). During this preliminary period, the mice had free access to the pellet diet (CE-2, CREA Japan Inc.) and water.

Test Methods — After the preliminary period, 22 mice were divided into two groups (each group, $n=11$ ), according to their weight on the seventh day after delivery. The mice were fed the experimental diets and water ad libitum for 12 weeks. Their weights were measured once a week and the total amount of food intake was measured every day.

The mice were deprived of diet for more than $18 \mathrm{hr}$ starting in the evening of the day prior to the end of the test period, although they still had access to water. After they were etherized, a blood sample was drawn from the abdominal artery. The mice were slaughtered and exsanguinated, following which; parametrical adipose tissue, liver and cecum were immediately removed and measured their weights. The liver was quickly frozen for storage and the cecum was stored at $4{ }^{\circ} \mathrm{C}$ in an anaerobic environment.

Analysis of Hepatic/Serum Triglyceride Level - The measurement of the serum triglyceride level was made using Triglyceride E-test Wako kit (Wako Pure Chemical Industries, Ltd., Osaka, Japan).

The frozen liver $(0.5 \mathrm{~g})$ was homogenized in Krebs Ringer phosphate buffer ( $\mathrm{pH} 7.4,4.5 \mathrm{ml}$ ), and the homogenate $(0.2 \mathrm{ml})$ was extracted with chloroform-methanol $(2: 1, \mathrm{v} / \mathrm{v}, 4 \mathrm{ml})$. The extract was concentrated under a nitrogen stream. The residue was determined by Triglyceride E-Test Wako kit. Measurement of the Organic Acids in the Cecal Contents — Organic acids in the cecal contents were analyzed by high performance liquid chromatography (HPLC). A mixture of the cecal contents $0.4 \mathrm{~g}$ and $1.5 \mathrm{ml}$ of water was homogenized and, to make the final concentration of organic acids between 0.2 and $30 \mathrm{mM}$, the homogenate was centrifuged at $9000 \times \mathrm{g}$ for $10 \mathrm{~min}$ at $4^{\circ} \mathrm{C}$. A mixture of $0.9 \mathrm{ml}$ of the supernatant and $0.1 \mathrm{ml}$ of $1 \mathrm{~mol} / \mathrm{l}$ of perchloric acid was allowed to stand for $2 \mathrm{hr}$ at $4^{\circ} \mathrm{C}$ and then passed through a filter with a pore size of $0.45 \mu \mathrm{m}$ (Nihon Millipore K.K., Tokyo, Japan). The quantification was executed according to HPLC method. The settings for the HPLC were as follows - Column: KC-811 Shodex (Showa Denko K.K., Tokyo, Japan), Temperature of the column: 35 or $60^{\circ} \mathrm{C}$, Mobile phase: $2 \mathrm{mM}$ perchloric acid, Flow rate: $0.5 \mathrm{ml} / \mathrm{min}$ and Refractive index detector.

Detection of Cecal Microbiota — The bacterial analysis of the cecal microbiota was carried out using a modified Mitsuoka method ${ }^{5)}$ and Terada et al. method. ${ }^{6}$ Five cecal contents in each group were used in this analysis. The objects of measurement were bifidobacteria, lactobacilli, lecithinase positive clostridia and total number of anaerobes. The media of blood-liver (BL), eggrth-gagnon (EG) (non-selective media) and clostridium welchii (CW) agar (selective media of lecithinase positive Clostridia) (Nissui Pharmaceutical Co., Ltd., Tokyo, Japan) were used in the determination of anaerobic bacteria and trypticase soy blood (TS) agar (non-selective media) was used in the determination of aerobic bacteria. The BL and EG agar were sealed in 
Table 2. Effect of MOS on Energy Intake, Final Weight and Parametrial Adipose Tissue

\begin{tabular}{lcc}
\hline \hline & Control & MOS \\
\hline Energy intake (kcal/animal/day) & $16.89 \pm 0.26$ & $\left.19.03 \pm 0.40^{a}\right)$ \\
Final weight (g/animal) & $55.48 \pm 2.03$ & $55.04 \pm 2.59$ \\
Parametrial adipose tissue weight (g/animal) & $3.64 \pm 0.23$ & $3.10 \pm 0.22$ \\
Parametrial adipose tissue \% (g/100 g body weight) & $6.54 \pm 0.31$ & $\left.5.59 \pm 0.31^{a}\right)$ \\
\hline \multicolumn{2}{c}{ Each value represents the mean \pm SEM $(n=11)$. MOS: mannooligosaccharides. $a$ ) Statistically } \\
significant from the control $(p<0.05)$.
\end{tabular}

Table 3. Effect of MOS on Liver Weight and Hepatic/Serum Triglyceride Level

\begin{tabular}{lcc}
\hline \hline & Control & MOS \\
\hline Liver weight $\%(\mathrm{~g} / 100 \mathrm{~g}$ body weight $)$ & $5.76 \pm 0.29$ & $5.19 \pm 0.29$ \\
Hepatic triglyceride $(\mathrm{mg} / \mathrm{g}$ liver $)$ & $84.23 \pm 6.87$ & $\left.59.96 \pm 5.58^{a}\right)$ \\
Serum triglyceride $(\mathrm{mg} / \mathrm{dl})$ & $155.74 \pm 16.3$ & $118.52 \pm 8.82$ \\
\hline \multicolumn{2}{c}{ Each value represents the mean \pm SEM $(n=11)$. MOS: mannooligosaccharides. $a$ ) Statistically } \\
significant from the control $(p<0.01)$.
\end{tabular}

airtight bags with Anaero-Packs (Mitsubishi Gas Chemical Company, Inc., Tokyo, Japan) and cultivated under anaerobic conditions. All cultures were incubated at $35^{\circ} \mathrm{C}$ for $48 \mathrm{hr}$. After incubation, each plate was examined for bacterial colonies. The identification was performed with colonial and cellular morphologies, a gram stain, spore formation and aerobic growth. The bacterial counts per gram of wet cecal contents were calculated and converted into a logarithm.

Analysis of Fecal Triglyceride Level _ The feces for three days in the examination period were collected. The feces $(0.15 \mathrm{~g})$ were extracted with chloroform-methanol $(2: 1, \mathrm{v} / \mathrm{v}, 4 \mathrm{ml})$. The extract was concentrated under a nitrogen stream. The residue was determined by Triglyceride E-Test Wako kit.

Statistical Analysis — The data obtained were expressed as a mean \pm the SEM. Statistical analysis was performed by the Student's $t$-test to determine significance. The level of statistical significance was set at $p<0.05$.

\section{RESULTS AND DISCUSSION}

\section{Effects on Food Consumption, Body Weight and Parametrial Fat Percentage}

Table 2 shows the average energy intake in the experimental period, body weight at the closing of the experiment, weight and percentage weight of the parametrial adipose tissue. All groups showed a steady growth in weight and not a single individual showed any sign of poor growth. The energy intake was significantly higher in the MOS group than that of the control group $(p<0.05)$. Contrarily, there was no statistically significant difference in the final body weight between the control group and MOS group. The percentage weight of the fat was significantly lower in the MOS group than that of the control group $(p<0.05)$. These results suggest that the administration of MOS may prevent fat accumulation induced by a high fat diet.

\section{Effects on the Liver Weight and Hepatic/Serum Triglyceride Level}

Table 3 shows the liver weight and hepatic/serum triglyceride. Compared with the control group, the MOS group showed a significantly lower hepatic triglyceride level $(p<0.01)$. A fatty liver is an indication of excessive triglyceride accumulation in the liver, triggered by an imbalance between fat consumption and synthesis in the organ. Long-term consumption of a high fat diet evidently induces the enlargement of the liver and fatty liver, ${ }^{7)}$ which we believe had also affected mice in this study. Kumao et al. demonstrated that MOS prevented the fatty liver based upon their findings on the percentage weight of the liver and hepatic triglyceride level in the obese rats induced by overeating. ${ }^{8)}$ Our study reconfirmed that the administration of MOS reduced the triglyceride level in the liver.

In this study, the amount of serum triglyceride was a lower tendency $(p=0.058)$ in the MOS group 
Table 4. Effect of MOS on Organic Acids and Microbiota in Cecal Contents

\begin{tabular}{|c|c|c|}
\hline & Control & MOS \\
\hline Cecal contents weight (g/animal) & $0.11 \pm 0.01$ & $0.10 \pm 0.02$ \\
\hline \multicolumn{3}{|l|}{ Organic acids (mg/g) } \\
\hline Acetate & $5.57 \pm 0.30$ & $6.90 \pm 0.41^{a)}$ \\
\hline Propionate & $1.67 \pm 0.23$ & $2.13 \pm 0.16$ \\
\hline$n$-Butyrate & $3.16 \pm 0.33$ & $3.34 \pm 0.36$ \\
\hline iso-Butyrate & $0.26 \pm 0.03$ & $0.30 \pm 0.02$ \\
\hline Valerate & $0.15 \pm 0.02$ & $\left.0.21 \pm 0.01^{a}\right)$ \\
\hline Lactate & $1.15 \pm 0.25$ & $0.74 \pm 0.13$ \\
\hline Succinate & $1.19 \pm 0.24$ & $1.25 \pm 0.24$ \\
\hline \multicolumn{3}{|l|}{ Microbiota $\left(\log _{10}\right.$ bacteria/g) } \\
\hline Bifidobacteria & $8.3 \pm 0.1(5)$ & $9.0 \pm 0.4(5)^{b)}$ \\
\hline Bacteroidaceae & $9.5 \pm 0.2(5)$ & $9.1 \pm 0.3(5)$ \\
\hline Clostridia & $6.6 \pm 0.3(5)$ & $6.0 \pm 0.4(5)^{b)}$ \\
\hline Lecithinase- positive Clostridia & $3.4 \pm 0.4(2)$ & $0(0)$ \\
\hline Enterobacteroidaceae & $4.8 \pm 0.8(5)$ & $3.7 \pm 1.0(5)^{b)}$ \\
\hline Lactobacilli & $8.0 \pm 0.6(5)$ & $8.5 \pm 0.2(5)$ \\
\hline Total bacteria & $9.6 \pm 0.2$ & $9.4 \pm 0.3$ \\
\hline Ratio of Bifidobacteria (\%) & $4.8 \pm 0.2$ & $35.4 \pm 7.40^{a)}$ \\
\hline
\end{tabular}

than that of the control group. The serum triglyceride level of the MOS group was approximately the same as that of the mice, the same strain as the MOS group, which were fed a regular diet $(105.3 \pm$ $11.5 \mathrm{mg} / \mathrm{dl}){ }^{7)}$ This result suggests that MOS might be effective in inhibiting hyperlipidemia caused by the intake of high fat foods. In relation to the mechanism for a decrease in the amount of hepatic triglyceride, one hypothesis might be that MOS played a role in the intestinal absorption of the triglyceride.

Han et al. found that lactosucrose, a type of oligosaccharide, had an anti-obesity property through inhibiting the intestinal absorption of the triglyceride as well as beta-monoglyceride, a fat metabolite. ${ }^{9)}$ Our previous studies showed that MOS were capable of inhibiting the absorption of fatty acids and delaying the absorption of lipids. ${ }^{4}$ Being a type of fat metabolite, the reduced absorption of fatty acids seems to lead to a decrease in the absolute volume of the triglyceride that is regenerated in the epithelium of the small intestine. Furthermore, a slower rate of triglyceride absorption is expected to inhibit accumulation of excess fat in the liver. Therefore, MOS might be effective to prevent the fatty liver and serum triglyceride elevation through the inhibition of triglyceride absorption in the small intestine.

\section{Effects on the Organic Acids and Cecal Microbiota, and Fecal Triglyceride Level}

Table 4 shows the results of organic acids and the cecal microbiota. MOS significantly promoted the growth of bifidobacteria, a type of beneficial bacteria, and the occupancy rate of the bifidobacteria increased significantly in the cecal microbiota $(p<$ 0.05 and $p<0.01$ respectively). As a consequence, the acetate as a fermentation product of intestinal bacteria significantly increased $(p<0.01)$. In contrast, the growth of clostridia, a type of harmful bacteria, decreased $(p<0.05)$.

Table 5 shows the energy intake, the fecal weight and fecal triglyceride level during a fecal sampling period. There was no difference in the energy intake and fecal weight between two groups. However, the fecal triglyceride level was significantly higher in the MOS group $(p<0.05)$.

It is generally known that organic acids produced from indigestible oligosaccharide activate the intestinal peristalsis and improve defecation. ${ }^{10)}$ The study by Tokunaga $e t$ al. wherein rats were administered fructooligosaccharides, a type of indigestible oligosaccharides, revealed that the oligosaccharides were able to decrease the gastrointestinal transit time. ${ }^{11)}$ This function is possibly attributable to sup- 
Table 5. Effect of MOS on Fecal Weight and the Fecal Triglyceride Level

\begin{tabular}{lcc}
\hline \hline & Control & MOS \\
\hline Energy intake (kcal/animal/day) & $16.64 \pm 0.84$ & $16.99 \pm 0.58$ \\
Fecal weight (g/animal/day) & $0.17 \pm 0.04$ & $0.18 \pm 0.03$ \\
Fecal triglyceride (mg/g/day) & $21.38 \pm 3.91$ & $\left.34.02 \pm 3.64^{a}\right)$ \\
\hline \multicolumn{2}{c}{ Each value represents the mean \pm SEM $(n=11)$. MOS: mannooligosaccharides. a) Statistically } \\
significant from the control $(p<0.05)$.
\end{tabular}

press the digestion and absorption of nutrients in the intestine. This study showed that the beneficial bacteria and organic acids were significantly increased by MOS intake, therefore, it is expected that MOS have the absorption depression effect in the intestine. It seems likely that absorption reduction by decreasing gastrointestinal transit time might be one of the factors for the increase of triglyceride excretion.

In addition, we confirmed that MOS reduce fat absorption in intestine. $\left.{ }^{4}\right)$ When fat absorption is inhibited in small intestine, it is believed that fat is excreted from the body rather than being absorbed in the large intestine. This might be another factor for explaining the significant increase in the level of triglyceride being excreted shown in this experiment.

In conclusion, this study showed that the administration of MOS decreased the fat accumulation in the parametrial adipose tissue and the liver while at the same time increased the amount of fat being excreted. These results indicate that MOS may prevent the fat storage through inhibiting the intestinal absorption of dietary fat in a high fat diet.

\section{REFERENCES}

1) Asano, I., Nakamura, Y., Hoshino, H., Aoki, K., Fujii, S., Imura, N. and Iino, H. (2001) Use of mannooligosaccharides from coffee mannan by intestinal bacteria. Nippon Nogeikagaku Kaishi, 75, 1077-1083.

2) Asano, I., Umemura, M., Fujii, S., Hoshino, H. and Iino, H. (2004) Effects of mannooligosaccharides from coffee mannan on fecal microflora and defecation in healthy volunteers. Food Sci. Technol. Res., 10, 93-97.

3) Asano, I., Fujii, S., Kaneko, M., Takehara, I. and
Fukuhara, I. (2006) Investigation of mannooligosaccharides blended coffee beverage on abdominal fat reduction in humans. Jap. J. Med. Pharm. Sci., 55, 93-103.

4) Kumao, T., Fujii, S., Ozaki, K. and Takao, I. (2005) Effects of diets with mannooligosaccharides from coffee mannan on fat in blood serum in healthy volunteers. Jap. J. Food Engineering, 6, 301-304.

5) Mitsuoka, T. (1982) A color atlas of anaerobic bacteria Bacterial, Shobunsha, Tokyo.

6) Terada, A., Hara, H., Ikegame, K., Sasaki, M. and Mitsuoka, T. (1994) Recommended method of enumeration of lecithinase-positive clostridia in human feces. Bifid Microflora, 13, 29-32.

7) Han, L.-K. Sumiyoshi, M., Takeda, T., Chihara, H., Nishikiori, T., Tsujita, T., Kimura, Y. and Okuda, H. (2000) Inhibitory effects of chondroitin sulfate prepared from salmon nasal cartilage on fat storage in mice fed a high-fat diet. International Journal of Obesity, 24, 1131-1138.

8) Kumao, T., Fujii, S., Ozaki, K. and Takao, I. (2005) Effects of diets containing mannooligosaccharides from coffee mannan on fat in blood serum and liver fat in (ZUC)-falfa rats. Jap. J. Med. Pharm. Sci., 54, 505-509.

9) Han, L.-K., Jing, L., Sumiyoshi, M., Tsujita, T., Kimura, Y., Zheng, Y.-N. and Okuda, H. (1999) Reduction in fat storage during $4 \mathrm{G}-\beta$-D-galactosylsucrose (lactosucrose) treatment in mice fed a high-fat diet. Journal of Traditional Med., 16, 6671.

10) Gibson, G. R. and Roberfroid, M. B. (1995) Dietary Modulation of the Human Colonic Microbiota: Introducing the concept of prebiotic. American Institute of Nutrition, 125, 1401-1412.

11) Tokunaga, T., Oku, T. and Hosoya, N. (1986) Influence of chronic intake new sweetener fructooligosaccharides (Neosuger) on growth and gastrointestinal function of the rat. J. Nutr. Sci. Vitaminol. (Tokyo), 32, 111-121. 